\title{
Mating Intelligence, Moral Virtues, and Methodological Vices
}

TOMISLAV BRACANOVIĆ

Department of Philosophy

University of Zagreb - Croatian Studies

\begin{abstract}
According to the 'mating intelligence' theory by evolutionary psychologist Geoffrey Miller, human morality is a system of sexually selected traits which serve as costly signals to the other sex about one's fitness and readiness to take care for possible offspring. Starting from the standard prediction of evolutionary psychology that sexual selection produces psychological sex differences in human mating strategies, 'mating intelligence' theory is analyzed for its compatibility with several psychological theories about sex differences in moral traits like moral reasoning, judgment and orientation. It is argued that the 'mating intelligence' theory, as a theory about the the evolution of morality, comes too dangerously close to being unfalsifiable because it embodies some auxiliary hypotheses and vague definitions which make it practically immune to every possible empirical finding concerning sex differences in human moral traits.
\end{abstract}

KEYWORDS: Mating intelligence, moral traits, sex differences, sexual selection, unfalsifiability.

From Charles Darwin to the present day, various biological mechanisms have been proposed as crucial for the explanation of the evolution of human moral traits: group selection (Darwin 2004 [1871]), kin selection (Hamilton 1964), reciprocal altruism (Trivers 1971), multilevel selection (Sober and Wilson 1998), among others. All these proposals, along with their methodological merits and shortcomings, received significant attention from contemporary evolutionary ethicists and philosophers of biology. However, one Darwinian account of evolution of morality - probably because it is a relatively new player in the field - hasn't been discussed too extensively so far. It is the 'mating intelligence' theory of the evolution of morality, proposed by evolutionary psychologist Geoffrey Miller (2000, 2007, 2008a).

Central to Miller's 'mating intelligence' view of the evolution of morality is the theory of sexual selection. According to this theory (first proposed by Darwin in his Descent of Man), certain disadvantageous traits of organisms that cannot be explained by natural selection can be explained by sexual selection. Sexual selection takes place in two basic forms: as intrasexual selection or 'male-male' competition - 
when members of one sex (usually males) compete with each other for access to mates - and as intersexual selection or 'mate-choice' - when members of one sex (usually females) choose to mate only with some individuals of the other sex on the basis of their 'attractive' and heritable traits. Although theory of sexual selection was either ignored or criticized by the majority of the most prominent evolutionists after Darwin, it regained its vigor during the final quarter of the $20^{\text {th }}$ century (see Cronin 1994, Spencer and Masters 1994).

Contrary to the majority of other Darwinian theories of evolution of morality, Miller claims that human moral traits should be explained as products of sexual selection. Since moral traits seem too costly to be explained by natural selection, too irrational to be explained by reciprocal altruism, and too wide in scope to be explained by either kin or group selection, Miller believes that we should view morality as product of sexual selection or, as he says, as 'a system of sexually selected handicaps'. Namely, moral traits (or moral virtues) like generosity, kindness and fidelity can be advantageous from the perspective of sexual selection, because they seem to be 'sexually attractive, and may serve as mental fitness indicators: they are judged as reliably revealing good mental health, brain efficiency, genetic quality, and capacity for sustaining cooperative sexual relationships as well as investing in children.' Miller thus came to believe that 'sexual selection shaped some of our distinctively human moral virtues as reliable fitness indicators' $(2007,98)$ and that we 'have the capacity for moral behavior and moral judgments today because our ancestors favored sexual partners who were kind, generous, helpful, and fair' (2000, 292).

It is hard not to compare Miller's view of human moral traits with the most cited example of sexual selection at work: the peacock's tail. Peacock's large and brightly colored tail, namely, may be a handicap to hiding or running and is as such disadvantageous or maladaptive from the perspective of natural selection. It has evolved, however, because it served as an 'advertisement' or 'costly signal' to peahens that its owner can afford and maintain such an energetically demanding and life endangering luxury, which obviously makes him a desirable sexual partner and father to one's offspring. Human moral traits, according to Miller, are rough analogues to peacock's tail. Although disadvantageous from the perspective of natural selection, they are advantageous from the perspective of sexual selection; they evolved as 'advertisements', 'expensive ornaments' or 'costly signals' to the other 
sex, suggesting that the particular individual is likely to be healthy, strong, and faithful sexual partner and devote parent to possible offspring.

Miller takes care to connect his theoretical proposals with as much as empirical data as possible, he announces a series of empirical predictions based on his theory, he promises to close some gaps in earlier Darwinian theories of morality, and even hopes to change the landscape of contemporary ethics by providing Darwinian support for the view of morality typical of the Aristotelian virtue theory (see esp. Miller 2007). Nevertheless, despite its actual and potential merits, his theory of evolution of morality seems open to certain objections revolving around the idea of empirical falsifiability. What follows is a critical reading of some Miller's points about sex differences and the nature of human moral traits. I will try to show that his 'mating intelligence' theory of evolution of moral traits remains too flexible and too immune to various mutually contradictory empirical findings from various branches of psychology. I am not suggesting that 'mating intelligence' theory has no virtues at all; all I would like to show is that, as an explanation of morality, it has some serious methodological and conceptual flaws.

Sexual selection tends to produce both physical and psychological sex differences and it is usually invoked when such differences need to be explained. The standard prediction of evolutionary psychology that 'sexes will differ in precisely those domains in which women and men have faced different sorts of adaptive problems' (Buss 1995, 164) seems reasonably well substantiated by studies showing that men and women do differ significantly with respect to their mate preferences (Buss 1989; see also Mealey 2000). As David Buss argues, '[g]iven the power of sexual selection, under which each sex competes for access to desirable mates of the other sex, it would be astonishing to find that men and women were psychologically identical in aspects of mating about which they have faced different problems of reproduction for millions of years' $(2003,211)$. Geoffrey Miller subscribes to the very same prediction and emphasizes: 'If evolution shaped psychological sex differences anywhere in the human mind, we should expect them most prominently in MI [mating intelligence] abilities, since MI is most closely associated with reproduction, and sex differences arise most prominently in reproductive strategies' (2008b, 379).

Apparently, Miller claims (a) that morality is the integral part of our 'mating intelligence' and (b) that psychological sex differences should be expected most prominently in the 'mating intelligence' (which is part of the larger body of 
reproductive strategies). This claim allows for the following common sense corollary: if psychological sex differences can be expected most prominently in our 'mating intelligence', and if morality is the integral part of our 'mating intelligence', then sex differences may be expected just as prominently in our moral traits and abilities. Moreover, if the presence of significant sex differences in human mating psychology indicates that human mating psychology evolved by means of sexual selection, then the absence of sex differences in human moral psychology should be taken as indicating that sexual selection had no influence on its evolution.

Before further analysis of the above corollary, it should be noted that the question of sex differences in moral traits and abilities (especially moral reasoning and judgment) is hardly new in moral and developmental psychology. Moreover, it is a question with a long and controversial tradition and what follows is a brief look at it.

In the late 1960s Lawrence Kohlberg proposed his theory of moral development and reasoning, claiming that moral development is a cognitive process consisting of six progressive stages. On the face of it, Kohlberg's tests and studies suggested male moral superiority because, on average, most boys and men seemed to have reached fourth stage of moral development, whereas most girls and women seemed to have reached only third stage (Kohlberg 1981, 1984). However, Kohlberg did not interpret this difference as sex specific in the biological sense, but explained it in terms of different socialization experiences of men and women. For Kohlberg, men and women have the same moral nature and the same natural moral abilities. The best known criticism of Kohlberg came from Carol Gilligan (1982) who claimed that women scored lower on Kohlberg's tests because those tests were male biased. According to Gilligan, his tests were formulated in terms of abstract principles, rules and justice and as such were unsuitable for the allegedly specific feminine moral orientation focused on personal approach, personal experience, nurturing and care. For Gilligan, important sex specific differences in moral orientation and moral reasoning do exist and, as she famously declared, women speak of moral matters 'in a different voice' than men.

Prompted by Gilligan's criticism of Kohlberg, Lawrence Walker (1984) performed the metaanalysis of earlier studies on sex differences in moral reasoning and claimed to have shown that sex differences in moral reasoning are actually nonsignificant and that Gilligan's criticism of Kohlberg was unfounded. Disputes continued when Diana Baumrind (1986) performed an analysis of Walker 
metaanalysis ('metametaanalysis'), claiming to have detected some flaws in it which cast doubt on its general conclusions. Contrary to Baumrind's view that some sex differences in moral reasoning do exist after all, the prevailing opinion today seems to be that 'the weight of current research does not support the idea that gender differences in moral reasoning or moral orientation exist' (Brabeck and Satiani 2002, 444).

In more recent times, neuroscience and ethics merged into a discipline called 'neuroethics', with researchers performing fMRI experiments on brains of people while they were dealing with specially designed moral dilemmas better known as ‘Trolley Problems' (see e.g. Greene et al. 2001). This search for neural mechanisms behind human moral judgment attracted a lot of attention and provoked serious discussion, but it revealed no significant sex differences (see e.g. Hauser et al. 2007). On the other hand, it is worth mentioning some psychological studies on sex differences in certain capacities that seem closely linked with the capacity for morality. For example, developmental psychologist David Geary argues that, probably thanks to sexual selection, women are better than men in social cognition and the Theory of Mind (ToM), i.e. in making inferences about the 'intentions, beliefs, emotional states, and likely future behavior of other individuals' (Geary 2002, 35). Although social cognition and ToM, strictly speaking, are not moral capacities, they are important prerequisites for morality, and if sex differences exist in social cognition and ToM, it would make sense to expect some parallel differences in moral capacities like moral reasoning, judgment or orientation.

Given this variety of psychological and philosophical answers to the question of sex differences in human moral traits, it is hard to say conclusively if there are any or how large or important are they. As it was already suggested, studies revealing certain sex differences in moral traits would fit nicely with the 'mating intelligence' view of morality. However, as we will see shortly, this is not necessarily so.

Although psychologists and philosophers tend to split their ways when it comes to the question of sex differences in various human moral traits, we can - for the sake of argument - speculate about some 'alternative empirical realities' and see how they might be related to the 'mating intelligence' theory of morality. Imagine two possible worlds: in possible world 1, significant sex differences in moral reasoning, judgment and orientation are discovered and confirmed, whereas in possible world 2 it is established with certainty that there are no sex differences in those traits 
whatsoever. Which world would be a more welcoming place for the 'mating intelligence' theory of morality?

In possible world 1, the world in which sex differences in moral reasoning and orientation do exist, these differences could be interpreted more or less straightforwardly as confirming the 'mating intelligence' theory. Sex differences would most likely square well with the standard prediction of evolutionary psychology according to which sexual selection produces not only physical, but also psychological sex differences. Moreover, if it turns out that some moral traits are better developed or more fine-tuned in women than in men (perhaps quasi-moral traits like ToM or social cognition as suggested by Geary), this would fit even better with the basic logic of the 'mating intelligence' theory. How this explanation could work is illustrated by Miller's explanation of another set of alleged sex differences: sex differences in verbal ability and language comprehension. On one hand, as Miller concedes, 'when sex differences do show up in human mental abilities, women typically show higher average verbal ability'; women, namely, 'comprehend more words on average, and this sex difference accounts for almost 5 percent of the individual variation in vocabulary size $(2000,375)$. On the other hand, as Miller observes, '[m]en write more books. Men give more lectures. Men ask more questions after lectures. Men dominate mixed-sex committee discussions. Men post more e-mail to Internet discussion groups' (2000, 376).

Miller explains the above sex differences with his 'male-display, femalechoice' logic. In short, sex differences in verbal abilities and language comprehension reveal that language evolved under sexual selection because men used language as a display (courtship) device, whereas women developed more acute language comprehension as an evaluation device. Basically, the suggestion is that language had the same function as the peacock's tail: 'Normally, sexual selection makes males better display-producers and females better display-discriminators. Peacocks can grow bigger tails, but peahens may be better at seeing and judging tails' (Miller 2000, 375). Apparently, the existence of sex differences is taken here as more or less direct confirmation of the hypothesis that human language evolved under sexual selection. Consequently, if we discover structurally similar sex differences in human moral traits and abilities - maybe with males as assertive moral-display producers and females as keen moral-display discriminators - 'mating intelligence' theory already has a convenient explanatory framework to account for them. 
Consider now the possible world 2, the world with no sex differences in moral traits and abilities. Relying on the logic of the previous explanatory framework (the one applied on verbal abilities and language comprehension), one could argue that the absence of sex differences in the moral domain contradicts Miller's 'mating intelligence' theory of evolution of morality. According to Miller, as we have seen, moral traits are part and parcel of our 'mating intelligence' and 'mating intelligence' shaped by sexual selection is the first place where sex differences are expected. However, if there are no sex differences in our moral traits, aren't we obliged to symmetrical conclusion that moral traits are not part and parcel of our "mating intelligence' and as such not shaped by sexual selection?

Miller would probably disagree with the above objection and he does seem to have some ready-made replies to it. One possible strategy for dealing with such objections can be found in his account of general and creative intelligence. According to Miller, namely, human general and creative intelligence were also shaped by sexual selection although they show no significant sex differences. In order to reconcile this fact with his general theory and predictions concerning sex differences, Miller explains the absence of sex differences in general and creative intelligence with the following three auxiliary hypotheses, or three factors 'that could have kept male human minds similar to female human minds despite strong sexual selection' (see Miller 2000, 89-97):

(1) Sex differences are leveled out to some extent as they are equally inherited by both male and female offspring. In a nutshell, both daughters and sons can inherit sexually selected traits from their fathers, just as they can inherit sexually selected traits from their mothers.

(2) Evolution of the mental capacity for producing sexually attractive behavior causes parallel evolution of the mental capacity for assessing that behavior. The point is that in order to asses certain sexually attractive traits in other sex one already has to have those traits; for example, in order to assess someone's intelligence or sense of humor, one already has to be intelligent or have sense of humor.

(3) Mental capacities for sexual choice evolved equally in men and women because, when looking for long-term partners, both sexes had to be choosy and to display their attractiveness and intelligence. Namely, although men and 
women do differ significantly in their preferences when it comes to short-term mating, they nevertheless seem to prefer practically the same traits in the other sex when it comes to long-term mating.

It is not my intention to assess the plausibility of the above auxiliary hypotheses. The only point I wish to make here is that the very same auxiliary hypotheses which provide convenient framework for explaining similarity of male and female general and creative intelligence can also provide the convenient framework for explaining human moral traits as products of sexual selection. Namely, even if it turns out that there are absolutely no sex differences in moral traits like moral reasoning, judgment or orientation, proponent of the 'mating intelligence' theory could still maintain that moral traits were sexually selected by employing some of these auxiliary hypothesis, i.e. by arguing that sex differences in moral traits were leveled out by some of the factors that leveled out sex differences in general and creative intelligence. To anticipate some of my concluding points, it seems that auxiliary hypotheses are invoked when counter-evidence needs to be reconciled with the general theory (as in the possible world 1), but not when they could complicate the nice match between the theory and other empirical observations (as in the possible world 2).

Even if the above auxiliary hypotheses can explain the absence of sex differences in general intelligence, it does not follow that they are sufficient to explain the alleged absence of sex differences in traits like moral judgment or moral reasoning. It is implausible to assume without further explanation, namely, that moral reasoning is just a special case or application of general intelligence. For example, according to influential social-intuitionist theory, "moral judgment is more a matter of emotion and affective intuition than deliberate reasoning' (Greene and Haidt 2002, 517; see also Haidt 2001). Views like these present special challenge to the 'mating intelligence' account of morality. Namely, if human moral reasoning is mediated by 'emotion and affective intuition' (as social-intuitionists claim), and if emotional mechanisms behind human mate preferences are significantly sexually differentiated (as evolutionary psychologists claim), why are there no traces of similar sexual differentiation in moral traits like moral reasoning or judgment? It is strange that Miller, on one hand, very freely interprets a series of highly distinct traits as moral traits or moral virtues (cognitive traits like 'intelligence', emotional traits like 'sympathy', even physical traits like 'beauty'), but on the other hand does not address 
theoretically important questions about the exact nature of and possible sex differences in moral reasoning or judgment. As we have seen, these questions are extensively discussed by both philosophers and psychologists and it is surprising that they do not appear in an ambitious evolutionary account of human morality like Miller's 'mating intelligence' theory.

What I basically wanted to emphasize in this article is that Miller's application of auxiliary hypotheses appears too arbitrary and that his 'mating intelligence' theory relies on two very different explanatory frameworks: one for mental traits with sex differences (traits like verbal abilities and language comprehension) and another one for mental traits without sex differences (traits like general and creative intelligence). When it comes to sexually differentiated traits, they are accepted as confirmations of the general theory ('male display, female choice'). When it comes to sexually undifferentiated traits, auxiliary hypotheses are introduced in order to reconcile this fact with the general theory. What remains unclear, however, is the contextual and apparently asymmetric logic behind the application of auxiliary hypotheses. Namely, if there are factors that kept 'male human minds similar to female human minds despite strong sexual selection', why did they level out sex differences in some, but not in other mental traits and abilities?

Does all of this mean that the 'mating intelligence' theory of morality is unfalsifiable? The charge of unfalsifiability, especially in its classical form (Popper 2002 [1935]) may sound obsolete and out of place. Namely, Miller is himself wellaware of the fact that sexual selection 'can potentially explain any aspect of human nature that scientists can notice' $(2000,11)$ and he readily admits that his 'sexual choice theory sometimes sounds as if it could explain anything, and hence explains nothing' (2000, 27). However, confession does not turn vices into virtues. Miller is much less humble, for example, when he announces that his theory can actually explain 'most of the things that human minds are uniquely good at, such as humor, story-telling, gossip, art, music, self-consciousness, ornate language, imaginative ideologies, religion, and morality' $(2000,18)$ or when he almost prophetically predicts that 'genetic evidence that will emerge in the coming years will probably render [his] ideas - even the apparently most speculative ones - fully testable in ways [he] cannot anticipate' $(2000,27)$.

Although the charge of unfalsifiability directed against certain claims of evolutionary psychology may be too generalized, overdemanding and replete with 
negative bias (Sesardic 2003), that does not imply that there is no force to it. It is always possible to avoid falsification of a theory by introducing certain auxiliary hypotheses and by using certain vague or ad hoc definitions. If these strategies of avoiding falsification are methodological vices, then the 'mating intelligence' theory, when applied to the evolution of morality, appears sinful in at least two ways. Firstly, as I have tried to show, the theory seems too adjustable to two contradictory observational results (to sex differences in moral traits both existing and not existing), and too compatible with too many different theories (with theories that do postulate significant sex differences in human moral traits and with those that don't). And secondly, the theory utilizes auxiliary hypotheses which, if necessary, could help explain possible absence of sex differences in human moral traits, but at the price of the questionable or at least unsubstantiated assumption that moral reasoning is no different from the general intelligence.

\section{REFERENCES}

Baumrind, D. 1986. 'Sex differences in moral reasoning: response to Walker's (1984) conclusion that there are none', Child Development 57(2): 511-521.

Brabeck, M.M. and Satiani, A. 2002. 'Feminist ethics and moral psychology', in J. Worell (ed.), Encyclopedia of Women and Gender: Sex Similarities and Differences and the Impact of Society on Gender (San Diego, CA: Academic Press), 439-446.

Buss, D.M. 1989. 'Sex differences in human mate preferences: evolutionary hypotheses tested in 37 cultures', Behavioral and Brain Sciences 12(1): 1-49.

Buss, D.M. 1995. 'Psychological sex differences: origins through sexual selection', American Psychologist 50(3): 164-168.

Buss, D.M. 2003. The Evolution of Desire: Strategies of Human Mating (New York: Basic Books).

Cronin, H. 1994. 'Sexual selection: historical perspectives', in E. Fox Keller and E.A. Lloyd (eds.), Keywords in Evolutionary Biology (Cambridge, Mass.: Harvard University Press), 286-293.

Darwin, C. 2004 [1871]. The Descent of Man (London: Penguin Books).

Geary, D.C. 2002. 'Sexual selection and sex differences in social cognition', in A.V. McGillicuddy-De Lisi and R. De Lisi (eds.), Biology, Society, and Behavior: The Development of Sex Differences in Cognition (Greenwich, CT: Ablex/Greenwood), 23-53.

Gilligan, C. 1982. In a Different Voice (Cambridge, Mass. and London: Cambridge University Press).

Greene, J.D., Sommerville, R.B., Nystrom, L.E., Darley, J.M., and Cohen, J.D. 2001. 'An fMRI investigation of emotional engagement in moral judgment', Science 293(5537): 2105-2108. 
Greene, J. and Haidt, J. 2002. 'How (and where) does moral judgment work?', Trends in Cognitive Sciences 6(12): 517-523.

Haidt, J. 2001. 'The emotional $\operatorname{dog}$ and its rational tail: a social intuitionist approach to moral judgment', Psychological Review 108(4): 814-834.

Hamilton, W.D. 1964. 'The genetical evolution of social behaviour, I-II', Journal of Theoretical Biology 7(1): 1-16, 17-52.

Hauser, M., Cushman, F., Young, L., Kang-Xing Jin, R., and Mikhail, J. 2007. 'A dissociation between moral judgments and justifications', Mind \& Language 22(1): 1-21.

Kohlberg, L.L. 1981. Essays on Moral Development I: The Philosophy of Moral Development (San Francisco, CA: Harper and Row).

Kohlberg, L.L. 1984. Essays on Moral Development II: The Psychology of Moral Development (San Francisco, CA: Harper and Row).

Mealey, L. 2000. Sex Differences: Developmental and Evolutionary Strategies (San Diego, CA: Academic Press).

Miller, G. 2000. The Mating Mind: How Sexual Choice Shaped the Evolution of Human Nature (London: Vintage).

Miller, G. 2007. 'Sexual selection for moral virtues', The Quarterly Review of Biology 82(2): 97-125.

Miller, G. 2008a. 'Kindness, fidelity, and other sexually selected virtues', in W. Sinnott-Armstrong (ed.), Moral Psychology, Volume 1. The Evolution of Morality: Adaptations and Innateness (Cambridge, Mass. and London: MIT Press), 208-243.

Miller, G. 2008b. 'Mating intelligence: frequently asked questions', in G. Geher and G. Miller (eds.), Mating Intelligence: Sex, Relationships, and the Mind's Reproductive System (New York, London: Lawrence Erlbaum Associates), 367-393.

Popper, K.P. 2002 [1935]. The Logic of Scientific Discovery (London and New York: Routledge).

Sesardic, N. 2003. 'Evolution of human jealousy: a just so story or a just-so criticism?', Philosophy of the Social Sciences 33(4): 427-443.

Sober, E. and Wilson, D.S. 1998. Unto Others: The Evolution and Psychology of Unselfish Behavior (London: Harvard University Press).

Spencer, H.G. and Masters, J.C. 1994. 'Sexual selection: contemporary debates', in E. Fox Keller and E.A. Lloyd (eds.), Keywords in Evolutionary Biology (Cambridge, Mass.: Harvard University Press), 294-301.

Trivers, R.L. 1971. 'The evolution of reciprocal altruism', Quarterly Review of Biology 46(1): 35-57.

Walker, L.J. 1984. 'Sex differences in the development of moral reasoning: a critical review', Child Development 55(3): 677-691. 